\title{
Microelements as risk factors for cancer of the lung and larynx
}

\author{
Katrzyna Jaworska-Bieniek,2, Satish Gupta ${ }^{1,2}$, Katarzyna Durda' ${ }^{1}$, Magdalena Muszynska' ${ }^{1}$, Grzegorz Sukiennicki ${ }^{1}$, \\ Elżbieta Jaworowska ${ }^{3}$, Tomasz Grodzki ${ }^{4}$, Mieczysław Sulikowski ${ }^{5}$, Piotr Woloszczyk ${ }^{6}$, Janusz Wójcik ${ }^{4}$, Jakub Lubiński ${ }^{3}$, \\ Cezary Cybulski ${ }^{1}$, Tadeusz Dębniak', Marcin Lener ${ }^{1}$, Steven A Narod, Ping Sun ${ }^{7}$, Jan Lubiński ${ }^{1}$, \\ Anna Jakubowska ${ }^{*}$
}

From Annual Conference on Hereditary Cancers 2012 Szczecin, Poland. 30-31 August 2012

Selenium deficiency has been suggested by several studies to be associated with cancer risk. We conducted a casecontrol study in Szczecin, a region of northwestern Poland, on 86 cases of lung cancer, 87 cases of laryngeal cancer and an equal number of healthy controls. We studied the serum level of selenium and genotypes for four variants in four selenoprotein genes (GPX1, GPX4, TXNRD2 and SEP15) and the odds of being diagnosed with lung or laryngeal cancer.

Among lung cancer cases, the mean selenium level was $63.2 \mu \mathrm{g} / \mathrm{l}$, compared to a mean level of $74.7 \mu \mathrm{g} / \mathrm{l}$ for their matched controls ( $\mathrm{p}<0.0001)$. Among laryngeal cancer cases, the mean selenium level was $64.8 \mu \mathrm{g} / \mathrm{l}$, compared to a mean level of $76.3 \mu \mathrm{g} / \mathrm{l}$ for their matched controls $(\mathrm{p}<$ $0.0001)$. Compared to a serum selenium value in the lowest of four categories $(\leq 60 \mu \mathrm{g} / \mathrm{l})$ a selenium level in the highest category $(>80 \mu \mathrm{g} / \mathrm{l})$ was associated with an odds ratio of 0.10 (95\% CI 0.03 to $0.34 ; \mathrm{p}=0.0002$ ) for lung cancer and 0.24 (95\% CI 0.10 to $0.59 ; \mathrm{p}=0.002)$ for laryngeal cancer. In four selenoproteins studied here we found a modest associations of genetic variants in GPX1 and GPX4 with lung and TXNRD2 with laryngeal cancer risk.

We analyzed iron (Fe) level in serum of 77 lung cancer patients and 77 matched controls. We did not find difference in mean Fe level between cases and controls (1053.05 $\mu \mathrm{g} / \mathrm{l}$ and $1059.39 \mu \mathrm{g} / \mathrm{l})$. However, we found that Fe level in the lowest and highest quartiles was associated with a significant lung risk enhancement when compared to a serum Fe level in the middle quartiles (OR 0.3, p 0.02). We also observed that the relationship between the level of Fe and Se could be an important factor for lung cancer risk.

\section{Conclusion}

1. Se is the strong marker of high risk of lung and laryngeal cancers and can be potentially used for detection of early cancers. Based on data showing higher Se supplementation as to be associated with lower cancer mortality (OR.55) Se supplementation should be considered to all patients with already diagnosed cancer.

2. Very low and very high Fe level seems to be associated with increased lung cancer risk

3. Most probably, for exact cancer risk assessment it will be necessary to analyze relationships between microelements, ie. Fe/Se ratio.

\section{Author details}

International Hereditary Cancer Centre, Department of Genetics and Pathology, Pomeranian Medical University, Szczecin, Poland. ${ }^{2}$ Postgraduate School of Molecular Medicine, Warsaw Medical University, Warsaw, Poland. ${ }^{3}$ Department of Otolaryngology and Laryngological Oncology, Pomeranian Medical University, Szczecin, Poland. ${ }^{4}$ Department of General Thoracic Surgery, Pomeranian Medical University, Szczecin, Poland. ${ }^{5}$ Maxillofacial Surgery, Pomeranian Medical University, Szczecin, Poland. ${ }^{6}$ Department of Toxicology and Molecular Pathobiochemistry, Pomeranian Medical University, Szczecin, Poland. `Women's College Research Institute, Toronto, ON, Canada.

Published: 10 December 2012

\section{doi:10.1186/1897-4287-10-S4-A2}

Cite this article as: Jaworska-Bieniek et al:: Microelements as risk factors for cancer of the lung and larynx. Hereditary Cancer in Clinical Practice 2012 10(Suppl 4):A2

${ }^{1}$ International Hereditary Cancer Centre, Department of Genetics and

Pathology, Pomeranian Medical University, Szczecin, Poland

Full list of author information is available at the end of the article

C 2012 Jaworska-Bieniek et al; licensee BioMed Central Ltd. This is an Open Access article distributed under the terms of the Creative 